\title{
Association between the FTO rs9939609 polymorphism and the metabolic syndrome in a non-Caucasian multi-ethnic sample Salam A Al-Attar ${ }^{1}$, Rebecca L Pollex ${ }^{1}$, Matthew R Ban ${ }^{1}$, T Kue Young ${ }^{2}$, Peter Bjerregaard ${ }^{3}$, Sonia S Anand ${ }^{4}$, Salim Yusuf ${ }^{4}$, Bernard Zinman', Stewart B Harris ${ }^{6}$, Anthony JG Hanley ${ }^{5,7}$, Philip W Connelly ${ }^{8}$, Murray W Huff 1,9 and Robert A Hegele*1,9
}

\begin{abstract}
Address: ${ }^{1}$ Vascular Biology Research Group, Robarts Research Institute, London, Ontario, Canada, ${ }^{2}$ Department of Public Health Sciences, University of Toronto, Ontario, Canada, ${ }^{3}$ National Institute of Public Health, Copenhagen, Denmark, ${ }^{4}$ Population Health Research Institute, McMaster University, Hamilton Health Sciences, Hamilton, Ontario, Canada, ${ }^{5}$ Department of Medicine, University of Toronto, and Samuel Lunenfeld Research Institute, Mount Sinai Hospital, Toronto, Ontario, Canada, ${ }^{6}$ Thames Valley Family Practice Research Unit, University of Western Ontario, London, Ontario, Canada, ${ }^{7}$ Department of Nutritional Sciences, University of Toronto, Toronto, Ontario, Canada, ${ }^{8}$ Department of Laboratory Medicine and Pathobiology, University of Toronto, and the Keenan Research Centre, Li Ka Shing Knowledge Institute, St. Michael's Hospital, Toronto, Ontario, Canada and 'Schulich School of Medicine and Dentistry, University of Western Ontario, London, Ontario, Canada

Email: Salam A Al-Attar - salattar@robarts.ca; Rebecca L Pollex - rpollex@robarts.ca; Matthew R Ban - mban@robarts.ca; T Kue Young - kue.young@utoronto.ca; Peter Bjerregaard - pb@si-folkesundhed.dk; Sonia S Anand - anands@mcmaster.ca; Salim Yusuf - yusufs@mcmaster.ca; Bernard Zinman - zinman@mshri.on.ca; Stewart B Harris - sharris1@uwo.ca; Anthony JG Hanley - anthony.hanley@utoronto.ca; Philip W Connelly - connellyp@smh.toronto.on.ca; Murray W Huff - mhuff@uwo.ca; Robert A Hegele* - hegele@robarts.ca

* Corresponding author
\end{abstract}

Published: I 3 March 2008

Cardiovascular Diabetology 2008, 7:5 doi:10.1 186/1475-2840-7-5

This article is available from: http://www.cardiab.com/content/7///5

(c) 2008 Al-Attar et al; licensee BioMed Central Ltd.

This is an Open Access article distributed under the terms of the Creative Commons Attribution License (http://creativecommons.org/licenses/by/2.0), which permits unrestricted use, distribution, and reproduction in any medium, provided the original work is properly cited.
Received: 24 January 2008

Accepted: 13 March 2008

\begin{abstract}
Background: The rs9939609 T>A single-nucleotide polymorphism (SNP) in the FTO gene has previously been found to be associated with obesity in European Caucasian samples. The objective of this study is to examine whether this association extends to metabolic syndrome (MetS) and applies in non-Caucasian samples.

Methods: The FTO rs9939609 SNP was genotyped in 2121 subjects from four different nonCaucasian geographical ancestries. Subjects were classified for the presence or absence of MetS according to the International Diabetes Federation (IDF) and National Cholesterol Education Program Adult Treatment Panel (NCEP ATP) III definitions.

Results: Carriers of $\geq$ I copy of the rs9939609 A allele were significantly more likely to have IDFdefined MetS (35.8\%) than non-carriers (3I.2\%), corresponding to a carrier odds ratio (OR) of I.23 (95\% confidence interval [Cl] I.0I to I.50), with a similar trend for the NCEP ATP III-defined MetS. Subgroup analysis showed that the association was particularly strong in men. The association was related to a higher proportion of rs9939609 A allele carriers meeting the waist circumference criterion; a higher proportion also met the HDL cholesterol criterion compared with wild-type homozygotes.
\end{abstract}

Conclusion: Thus, the FTO rs9939609 SNP was associated with an increased risk for MetS in this multi-ethnic sample, confirming that the association extends to non-Caucasian population samples. 


\section{Background}

The metabolic syndrome (MetS) is a clinical entity characterized by abdominal obesity, hypertension, hypertriglyceridemia, depressed plasma high-density lipoprotein (HDL) cholesterol and elevated glucose $[1,2]$. MetS is common, and will likely become even more pervasive, considering the poor lifestyle habits prevalent in many societies today. While the increased prevalence of MetS is primarily related to an imbalance between caloric intake and expenditure, genetic factors are also likely to be important. Each defining component has been previously associated with genetic factors, suggesting that genetic factors might underlie the overall MetS both independently and through more complex interactions [3]. While the precise definition of MetS is controversial, there is no question that the MetS concept has proven to be valuable clinically $[4,5]$.

A potential candidate underlying genetic susceptibility to MetS is the FTO (fat mass and obesity associated) gene, encoding the human analogue of fused toes in mice. The FTO gene encodes a 2-oxoglutarate-dependent nucleic acid demethylase that is present in many tissues, but most abundant in the hypothalamus, the control center of energy balance [6]. Studies in mice showing that Fto mRNA levels are regulated by feeding and fasting have provided a mechanistic link between FTO and body weight and energy homeostasis [6]. Human population genetic studies have found FTO single nucleotide polymorphisms (SNPs) to be associated with type 2 diabetes [7] and obesity [8-11]. The FTO rs9939609 SNP is of particular interest since it was found to be associated with obesity through independent studies of large Caucasian populations [8-11]. Since obesity is one of the key features of MetS, we wondered whether this association signal could be found with the complex trait of MetS and whether the association could be detected across other non-Caucasian populations. Thus, the purpose of this study was to examine the FTO rs9939609 SNP as a potential genetic candidate for MetS, defined by both the National Cholesterol Education Program Adult Treatment Panel III (NCEP ATP III) and the International Diabetes Federation (IDF) criteria, in a sample derived from multiple non-Caucasian geographic ancestries.

\section{Methods \\ Study subjects}

The multi-ethnic study included Canadians of South Asian and Chinese descent, Oji-Cree (Ontario, Canada), and Inuit from Greenland. All subjects for the current study were collected from one of the following population studies: 1) the Study of Health Assessment and Risk in Ethnic Groups [12]; 2) the Sandy Lake Health and Diabetes Project [13]; and 3) the Greenland Population Study [14]. The details of these studies have been described pre- viously [12-14]. Signed informed consent was obtained from all participants and the study was approved by the University of Western Ontario Ethics Review Board (protocol \#7920E). For the current analysis, the number of subjects $\geq 18$ years of age with both sufficient DNA for FTO genotype determination and a complete set of data for MetS diagnosis included 325 South Asians, 299 Chinese, 400 Oji-Cree, and 1097 Greenland Inuit; a total of 2121 subjects (53.9\% female). There was no exclusion based on diabetes status.

\section{Physical measurements}

Measurements of waist circumference, blood pressure, fasting analytes, including venous plasma glucose, serum cholesterol, triglycerides (TG), low-density lipoprotein (LDL) cholesterol, and HDL cholesterol were performed as described [12-14].

\section{Metabolic syndrome classification}

According to the NCEP ATP III criteria [1], MetS was identified if a subject had $\geq 3$ of: 1) increased waist circumference ( $>102 \mathrm{~cm}$ [ $>40$ inches] for men, $>88 \mathrm{~cm}$ [ $>35$ inches] for women); 2 ) elevated plasma TG $(\geq 1.69 \mathrm{mmol} / \mathrm{L}[\geq$ $150 \mathrm{mg} / \mathrm{dL}]) ; 3)$ low plasma HDL cholesterol $(<1.04$ $\mathrm{mmol} / \mathrm{L}[<40 \mathrm{mg} / \mathrm{dL}]$ for men, $<1.29 \mathrm{mmol} / \mathrm{L}[<50 \mathrm{mg} /$ $\mathrm{dL}$ ] for women); 4) hypertension ( $\geq 130 / \geq 85 \mathrm{mmHg}$ ) or current medication; or 5$)$ impaired fasting glucose $(\geq 6.1$ $\mathrm{mmol} / \mathrm{L}[\geq 110 \mathrm{mg} / \mathrm{dL}])$.

The IDF criteria [15] identifies MetS for subjects with central obesity, according to ethnic specific guidelines (waist circumference for South Asians and Chinese $\geq 90 \mathrm{~cm}$ for men, $\geq 80 \mathrm{~cm}$ for women), plus any two of: 1) elevated plasma TG $(\geq 1.69 \mathrm{mmol} / \mathrm{L}[\geq 150 \mathrm{mg} / \mathrm{dL}]) ; 2)$ low plasma HDL cholesterol $(<1.04 \mathrm{mmol} / \mathrm{L}[<40 \mathrm{mg} / \mathrm{dL}]$ for men, $<1.29 \mathrm{mmol} / \mathrm{L}$ [ $<50 \mathrm{mg} / \mathrm{dL}]$ for women); 3) hypertension $(\geq 130 / \geq 85 \mathrm{mmHg}$ ) or current medication; or 4) impaired fasting glucose $(\geq 5.6 \mathrm{mmol} / \mathrm{L}[\geq 100 \mathrm{mg} / \mathrm{dL}])$ or previously diagnosed type 2 diabetes. Since no quantitative thresholds exist yet for aboriginal populations, these subjects were also evaluated using the South Asian and Chinese threshold values for waist circumference.

\section{Genotyping of the FTO polymorphism}

Detection of the FTO SNP rs9939609 was carried out using a validated TaqMan genotyping assay (Assay ID C_25638153_10; Applied Biosystems, Foster City, CA). SNP genotyping was performed using an allelic discrimination assay (TaqMan ${ }^{\circledR}$ SNP Genotyping Assays, Applied Biosystems, Foster City, CA) using the 7900HT Fast RealTime PCR System and genotypes were read using automated software (SDS 2.3, Applied Biosystems, Foster City, $\mathrm{CA})$. Reactions were run in $5 \mu \mathrm{L}$ volumes using an amplification protocol of $95^{\circ} \mathrm{C}$ for 10 minutes, followed by 50 cycles of $95^{\circ} \mathrm{C}$ for 15 seconds, then $60^{\circ} \mathrm{C}$ for 1.5 minutes. 


\section{Statistical analysis}

SAS version 9.1 (SAS Institute, Cary, NC) was used for all statistical comparisons. Data are presented as means \pm standard deviation (SD) or as percentages for discrete variables. Between-group differences in discrete variables were analyzed using $\chi^{2}$ analysis and odds ratios (OR) were calculated using the "case-control" method in the FREQ procedure in SAS. Differences in quantitative traits were analyzed by ANOVA, using the general linear model, adjusted for age. The significance of deviations of observed genotype frequencies from those predicted by the Hardy-Weinberg equation were evaluated with $\chi^{2}$ tests. The rs9939609 T>A genotypes were included in the analysis as a dichotomous variable, in both dominant and recessive models. Statistical significance was taken at a Pvalue $<0.05$ for all comparisons.

\section{Results}

Table 1 shows the demographic and metabolic characteristics of the populations included in the study. The FTO rs9939609 A allele frequencies were 0.32, 0.12, 0.066, and 0.18 , for the South Asians, Chinese, Oji-Cree, and Greenland Inuit, respectively. The genotype frequencies did not deviate from the Hardy-Weinberg predictions (data not shown).

Analysis across the 4 study populations indicated that FTO rs9939609 A allele carriers had an increased risk of MetS, according to the IDF definition (carrier OR 1.23, $95 \%$ CI 1.01 to $1.50, P=0.036$ ) (Table 2). Subgroup analysis of females showed that the carrier OR was 1.05 (95\% CI 0.80 to $1.38, P=$ NS [0.74]). Subgroup analysis of males showed that the carrier OR was 1.46 (95\% CI 1.10 to $1.94, P=0.0081)$. By individual ethnic populations, a significant increased risk for MetS was observed for FTO rs9939609 A allele carriers only in the South Asian group $(P=0.027)$. Analysis of the NCEP ATP III definition for MetS showed a similar trend towards increased risk for FTO rs9939609 A allele carriers compared to TT homozygotes (carrier OR 1.26, 95\% CI 1.02 to $1.57, P=0.036$ ) (Table 2). A significant increased risk for NCEP ATP III MetS was observed for FTO rs9939609 A allele carriers among Greenland Inuit $(P=0.037)$.

No significant increased risk of MetS was observed overall for AA homozygotes, for either the IDF or NCEP ATP III definitions, upon repeating the analyses using a recessive model for the FTO rs9939609 A allele. The non-significant trends suggested that sample numbers were insufficient for detecting an association with this particular trait.

Analysis of the entire sample revealed no significant increase in blood pressure, plasma triglycerides or glucose levels (Table 2). However, meta-analysis indicated that significantly more FTO rs9939609 A allele carriers met the
Table I: Clinical and biochemical data of subjects

\begin{tabular}{|c|c|c|c|}
\hline & Male & Female & $P$-value \\
\hline Greenland Inuit & $n=486$ & $n=622$ & \\
\hline age (years) & $46.2 \pm 12.9$ & $45.8 \pm 13.1$ & NS $(0.60)$ \\
\hline BMI $\left(\mathrm{kg} / \mathrm{m}^{2}\right)$ & $26.2 \pm 4.6$ & $26.7 \pm 5.4^{2}$ & NS $(0.072)$ \\
\hline waist $(\mathrm{cm})$ & $91.1 \pm 12.2$ & $88.1 \pm 13.5$ & 0.0001 \\
\hline systolic BP (mmHg) & $120 \pm 17$ & $119 \pm 20$ & NS $(0.14)$ \\
\hline diastolic BP $(\mathrm{mmHg})$ & $74 \pm 11$ & $72 \pm 11$ & $<0.0001$ \\
\hline total cholesterol (mmol/L) & $5.99 \pm 1.18$ & $6.02 \pm 1.13$ & NS (0.77) \\
\hline triglycerides (mmol/L) & $1.15 \pm 0.66$ & $1.12 \pm 0.61$ & NS $(0.090)$ \\
\hline LDL cholesterol (mmol/L) & $3.90 \pm 1.091$ & $3.89 \pm 1.06^{2}$ & NS $(0.67)$ \\
\hline HDL cholesterol (mmol/L) & $1.56 \pm 0.49$ & $1.62 \pm 0.42$ & 0.0015 \\
\hline fasting glucose (mmol/L) & $5.83 \pm 0.89$ & $5.76 \pm 1.34$ & NS $(0.21)$ \\
\hline MetS (\%) & 12.1 & 17.0 & 0.017 \\
\hline Oji-Cree & $n=218$ & $n=291$ & \\
\hline age (years) & $35.9 \pm 14.5$ & $35.7 \pm 14.7$ & NS $(0.85)$ \\
\hline BMI $\left(\mathrm{kg} / \mathrm{m}^{2}\right)$ & $26.8 \pm 4.6$ & $29.1 \pm 5.5$ & $<0.0001$ \\
\hline waist $(\mathrm{cm})$ & $96.9 \pm 12.2$ & $95.0 \pm 11.9$ & NS $(0.073)$ \\
\hline systolic BP (mmHg) & $122 \pm 14$ & $118 \pm 16$ & $<0.0001$ \\
\hline diastolic BP $(\mathrm{mmHg})$ & $70 \pm 12$ & $67 \pm 10$ & $<0.0001$ \\
\hline total cholesterol (mmol/L) & $4.83 \pm 0.98$ & $4.59 \pm 0.82$ & 0.0001 \\
\hline triglycerides (mmol/L) & $1.63 \pm 0.85$ & $|.51 \pm 0.7|$ & 0.0003 \\
\hline LDL cholesterol (mmol/L) & $2.91 \pm 0.82^{3}$ & $2.62 \pm 0.65^{4}$ & $<0.0001$ \\
\hline HDL cholesterol (mmol/L) & $1.19 \pm 0.30$ & $1.28 \pm 0.28$ & $<0.0001$ \\
\hline fasting glucose $(\mathrm{mmol} / \mathrm{L})$ & $6.73 \pm 3.25$ & $6.77 \pm 3.50$ & NS $(0.61)$ \\
\hline MetS (\%) & 30.3 & 39.2 & 0.028 \\
\hline South Asian & $n=180$ & $n=147$ & \\
\hline age (years) & $49.9 \pm 8.9$ & $49.0 \pm 9.6$ & NS $(0.37)$ \\
\hline BMI $\left(\mathrm{kg} / \mathrm{m}^{2}\right)$ & $26.1 \pm 4.3^{5}$ & $26.5 \pm 3.8$ & NS $(0.37)$ \\
\hline waist $(\mathrm{cm})$ & $94.7 \pm 9.7$ & $86.0 \pm 10.6$ & $<0.0001$ \\
\hline systolic BP (mmHg) & $121 \pm 16$ & $117 \pm 19$ & 0.034 \\
\hline diastolic BP $(\mathrm{mmHg})$ & $80 \pm 12$ & $71 \pm 10$ & $<0.0001$ \\
\hline total cholesterol (mmol/L) & $5.26 \pm 0.98$ & $5.15 \pm 0.94$ & NS $(0.4 I)$ \\
\hline triglycerides (mmol/L) & $2.05 \pm 1.31$ & $1.92 \pm 1.27$ & NS $(0.30)$ \\
\hline LDL cholesterol (mmol/L) & $3.45 \pm 0.846$ & $3.18 \pm 0.797$ & 0.0069 \\
\hline HDL cholesterol (mmol/L) & $0.95 \pm 0.26$ & $1.13 \pm 0.32$ & $<0.0001$ \\
\hline fasting glucose (mmol/L) & $5.95 \pm 1.89$ & $5.49 \pm 1.58$ & 0.020 \\
\hline MetS (\%) & 31.1 & 34.0 & NS $(0.38)$ \\
\hline Chinese & $n=148$ & $n=|5|$ & \\
\hline age (years) & $48.8 \pm 9.3$ & $46.6 \pm 8.4$ & 0.030 \\
\hline BMI $\left(\mathrm{kg} / \mathrm{m}^{2}\right)$ & $25.2 \pm 3.4$ & $22.7 \pm 3.5$ & $<0.0001$ \\
\hline waist $(\mathrm{cm})$ & $89.6 \pm 9.1$ & $75.2 \pm 7.9$ & $<0.0001$ \\
\hline systolic BP (mmHg) & $122 \pm 17$ & $112 \pm 20$ & 0.022 \\
\hline diastolic $\mathrm{BP}(\mathrm{mmHg})$ & $80 \pm 10$ & $70 \pm 12$ & $<0.0001$ \\
\hline total cholesterol (mmol/L) & $5.29 \pm 1.00$ & $4.85 \pm 0.84$ & 0.0057 \\
\hline triglycerides (mmol/L) & $2.14 \pm 1.61$ & $1.38 \pm 1.03$ & 0.0055 \\
\hline LDL cholesterol (mmol/L) & $3.34 \pm 0.84^{8}$ & $2.90 \pm 0.71^{9}$ & 0.0006 \\
\hline HDL cholesterol (mmol/L) & $1.03 \pm 0.29$ & $1.33 \pm 0.36$ & $<0.0001$ \\
\hline fasting glucose (mmol/L) & $5.44 \pm 1.29$ & $4.98 \pm 0.60$ & 0.016 \\
\hline MetS (\%) & 28.4 & 10.6 & 0.0003 \\
\hline
\end{tabular}

$I_{n}=483,{ }^{2} n=620,{ }^{3} n=216,{ }^{4} n=289,{ }^{5} n=179,{ }^{6} n=169,7^{7} n=141,{ }^{8} n=139,{ }^{9} n=$ 148

Abbreviations: BMI, body mass index; BP, blood pressure; LDL, low-density lipoprotein; HDL, high-density lipoprotein; MetS, metabolic syndrome; NS, not significant.

Data are means \pm standard deviation (SD). $P$-values are adjusted for age; $P$-values for blood pressure, cholesterol, triglycerides, LDL cholesterol, HDL cholesterol, and glucose are also adjusted for BMI. 
Table 2: Metabolic syndrome and metabolic syndrome component prevalence in subjects when classified in accordance to their genotype of the FTO rs9939609 T>A polymorphism

\begin{tabular}{|c|c|c|c|c|}
\hline & TT & AA \& AT & OR (95\% Cl) & P-value \\
\hline Overall $N=2121$ & 1482 & 639 & & \\
\hline IDF MetS (\%) & 31.2 & 35.8 & $1.23(1.01,1.50)$ & 0.036 \\
\hline South Asian & 36.8 & 49.1 & $1.66(1.06,2.58)$ & 0.027 \\
\hline Chinese & 24.6 & 22.4 & $0.89(0.46,1.69)$ & 0.71 \\
\hline Oji-Cree & 48.9 & 51.9 & $1.13(0.63,2.03)$ & 0.68 \\
\hline Greenland Inuit & 23.9 & 29.4 & $1.33(0.99,1.77)$ & 0.051 \\
\hline NCEP ATP III MetS (\%) & 21.1 & 25.2 & $1.26(1.02,1.57)$ & 0.036 \\
\hline South Asian & 28.3 & 35.8 & $1.42(0.88,2.27)$ & 0.15 \\
\hline Chinese & 18.5 & 22.4 & $\mathrm{I} .27(0.65,2.46)$ & 0.48 \\
\hline Oji-Cree & 36.2 & 40.4 & $1.19(0.66,2.17)$ & 0.56 \\
\hline Greenland Inuit & 13.3 & 18.2 & $1.44(1.02,2.04)$ & 0.037 \\
\hline MetS BP (\%) & 30.3 & 33.2 & $1.14(0.94,1.39)$ & 0.19 \\
\hline South Asian & 35.5 & 33.0 & $0.89(0.56, I .4 I)$ & 0.62 \\
\hline Chinese & 32.8 & 40.3 & $1.39(0.79,2.43)$ & 0.25 \\
\hline Oji-Cree & 27.6 & 19.2 & $0.63(0.30,1.30)$ & 0.20 \\
\hline Greenland Inuit & 29.7 & 34.0 & $1.22(0.93,1.60)$ & 0.16 \\
\hline MetS Triglycerides (\%) & 25.0 & 26.5 & I.08 (0.87, I.34) & 0.47 \\
\hline South Asian & 46.1 & 46.8 & $\mathrm{I} .03(0.67, \mathrm{I} .60)$ & 0.89 \\
\hline Chinese & 38.8 & 31.3 & $0.72(0.40,1.29)$ & 0.27 \\
\hline Oji-Cree & 33.1 & 40.4 & $1.37(0.76,2.49)$ & 0.30 \\
\hline Greenland Inuit & 12.7 & 13.3 & $1.05(0.72, \mathrm{I} .54)$ & 0.79 \\
\hline MetS HDL (\%) & 33.7 & 39.6 & $1.29(1.07,1.56)$ & 0.0089 \\
\hline South Asian & 69.1 & 71.7 & $1.13(0.70,1.83)$ & 0.61 \\
\hline Chinese & 51.7 & 61.2 & $\mathrm{I} .47(0.85,2.56)$ & 0.17 \\
\hline Oji-Cree & 45.7 & 59.6 & $\mathrm{I} .75(0.97,3.17)$ & 0.061 \\
\hline Greenland Inuit & 15.3 & 16.4 & $1.09(0.77,1.53)$ & 0.64 \\
\hline MetS Glucose (\%) & 45.3 & 47.7 & $1.10(0.92,1.33)$ & 0.30 \\
\hline South Asian & 25.7 & 34.1 & $\mathrm{I} .50(0.93,2.43)$ & 0.098 \\
\hline Chinese & 17.2 & 20.9 & I.27 $(0.64,2.50)$ & 0.49 \\
\hline Oji-Cree & 53.5 & 44.2 & $0.69(0.38,1.24)$ & 0.21 \\
\hline Greenland Inuit & 54.1 & 60.2 & $1.28(0.99,1.66)$ & 0.059 \\
\hline MetS Waist (IDF) (\%) & 60.9 & 65.0 & $1.19(0.98,1.44)$ & 0.080 \\
\hline South Asian & 64.5 & 75.1 & $1.67(1.03,2.69)$ & 0.036 \\
\hline Chinese & 34.9 & 32.8 & $0.91(0.51,1.62)$ & 0.75 \\
\hline Oji-Cree & 81.0 & 78.9 & $0.87(0.43,1.79)$ & 0.71 \\
\hline Greenland Inuit & 58.9 & 64.0 & $1.24(0.95,1.61)$ & 0.11 \\
\hline $\mathrm{BMI}>33$ kg/m² (\%) & 8.1 & 10.6 & $1.35(0.99,1.84)$ & 0.060 \\
\hline South Asian & 4.0 & 5.8 & $1.48(0.53,4.18)$ & 0.45 \\
\hline Chinese & 2.2 & 1.5 & $0.69(0.079,5.99)$ & 0.73 \\
\hline Oji-Cree & 13.5 & 26.9 & $2.36(1.19,4.68)$ & 0.012 \\
\hline Greenland Inuit & 8.3 & 12.4 & $1.57(1.04,2.36)$ & 0.032 \\
\hline
\end{tabular}


MetS criteria for depressed HDL cholesterol $(P=0.0089)$, and there was a nonsignificant trend towards increased waist circumference and increased BMI for FTO rs9939609 A allele carriers $(P=0.080$ and 0.060 , respectively) (Table 2).

\section{Discussion}

Our study of FTO as a candidate gene for MetS in a sample from multiple non-Caucasian geographical ancestries showed 1) significant association with the FTO gene, with rs9939609 A allele carriers, particularly males, having an increased risk of MetS (carrier OR 1.23, 95\% CI 1.01 to 1.50; $P=0.036$ ) (Table 2); and 2) this association was related to higher proportion of subjects with depressed HDL cholesterol and a trend towards increased waist circumference. Similar trends were observed for the NCEP ATP III definition of MetS.

This is the first report of an association between the FTO rs9939609 A allele and MetS. Furthermore, it extends the association of this allele beyond Caucasian samples. Although the observation may help understand the molecular etiology of MetS, this association requires replication in larger studies, considering the possibility of a spurious association due to population stratification or another such limitation [16]. Despite considerations regarding sample size however, the results reaffirm the established association between the FTO rs9939609 A allele with obesity in past findings [8-11]. However, MetS is a complex disorder, and only a few of the previously associated genes, such as APOC3 and PPARG, have been replicated in more than one study sample [4]. Aside from the need to replicate the FTO association in other larger study samples, the mechanism underlying the association also needs to be investigated. The mechanism underlying the association may be related to: 1) a direct function of FTO [6] or 2) linkage disequilibrium of the tested variant with another causative change in a gene near the FTO locus.

Analysis of the overall sample indicated that significantly more FTO rs9939609 A allele carriers met the MetS criteria for depressed HDL cholesterol $(P=0.0089)$ than non-carriers. In addition, values were close to significance also for increased waist circumference $(P=0.080)$ and increased BMI $(P=0.060)$ among A allele carriers (Table 2$)$. This indicates that the association of the FTO rs9939609 A allele with the MetS was related in part to both the obesity component, but also the HDL component, suggesting that this genetic marker may have a broader relationship with individual components of this complex trait.

Although the meta-analysis across the four non-Caucasian study populations showed an association between MetS and the common rs9939609 SNP in FTO, analyses by individual ethnic populations indicated a significant increased risk for MetS only among the South Asians (IDF definition) and Greenland Inuit (NCEP ATP III definition). Thus, the overall association is primarily due to these two populations, with little influence from the Chinese and Oji-Cree. Again, replication of the FTO association in other larger study samples is essential for clarification. Further evidence against an association for the Chinese can be found in a recent study of 3,210 unrelated Chinese Han subjects from Shanghai and Beijing where no association found between the rs9939609 SNP and obesity [17].

In summary, we report an association between MetS and the common rs9939609 SNP in FTO. The observed consistent association between MetS and FTO in a non-Caucasian multi-ethnic study group, including populations which differ considerably in MetS prevalence, strengthens the likelihood that the FTO locus is related to obesity and MetS. Future replication of this association in larger sized samples and devising functional molecular studies will further enhance the validity of association and the causative relationship between the FTO variant and MetS.

\section{Competing interests}

The author(s) declare that they have no competing interests.

\section{Authors' contributions}

SAA and RLP participated in the experimental design, data acquisition and analysis, interpretation of results, and manuscript writing. MRB participated in the analysis of the data. TKY, PB, SSA, SY, BZ, SBH, AJGH, PWC, and $\mathrm{MWH}$ were involved in the provision of patient samples and/or clinical data. RAH participated in the experimental design, data analysis and interpretation of results and manuscript writing. All authors approved the final manuscript.

\section{Acknowledgements}

$\mathrm{RAH}$ is supported by the Jacob J. Wolfe Distinguished Medical Research Chair, the Edith Schulich Vinet Canada Research Chair (Tier I) in Human Genetics, a Career Investigator award from the Heart and Stroke Foundation of Ontario (Cl-57/0), and operating grants from the Canadian Institutes for Health Research (MOP-I3430, MOP-39533, MOP-39833), the Heart and Stroke Foundation of Ontario (PRG-5967, NA-6059, T-6018), the Ontario Research Fund and by Genome Canada through the Ontario Genomics Institute. SAA is the recipient of the Master's Studentship Award from the Heart and Stroke Foundation of Ontario.

\section{References}

I. Executive Summary of The Third Report of The National Cholesterol Education Program (NCEP) Expert Panel on Detection, Evaluation, and Treatment of High Blood Cholesterol In Adults (Adult Treatment Panel III). JAMA 200I, 285(19):2486-2497.

2. Eckel RH, Grundy SM, Zimmet PZ: The metabolic syndrome. Lancet 2005, 365(9468): I4I5-I428. 
3. Groop L: Genetics of the metabolic syndrome. Br J Nutr 2000, 83 Suppl I:S39-48.

4. Pollex RL, Hegele RA: Genetic determinants of the metabolic syndrome. Nat Clin Pract Cardiovasc Med 2006, 3(9):482-489.

5. Yuan G, Hegele RA: Genetic forms of the cardiometabolic syndrome: What can they tell the clinician? JCMS 2007 2(I):45-48.

6. Gerken T, Girard CA, Tung YC, Webby CJ, Saudek V, Hewitson KS, Yeo GS, McDonough MA, Cunliffe S, McNeill LA, Galvanovskis ], Rorsman P, Robins P, Prieur X, Coll AP, Ma M, Jovanovic Z, Faroogi IS, Sedgwick B, Barroso I, Lindahl T, Ponting CP, Ashcroft FM, O'Rahilly S, Schofield C]: The obesity-associated FTO gene encodes a 2-oxoglutarate-dependent nucleic acid demethylase. Science 2007, 3 |8(5855): | 469-1472.

7. Horikoshi M, Hara K, Ito C, Shojima N, Nagai R, Ueki K, Froguel P, Kadowaki T: Variations in the HHEX gene are associated with increased risk of type 2 diabetes in the Japanese population. Diabetologia 2007, 50(I 2):246|-2466.

8. Genome-wide association study of 14,000 cases of seven common diseases and 3,000 shared controls. Nature 2007, 447(7| 45):66|-678.

9. Frayling TM, Timpson NJ, Weedon MN, Zeggini E, Freathy RM, Lindgren CM, Perry JR, Elliott KS, Lango H, Rayner NW, Shields B, Harries LW, Barrett JC, Ellard S, Groves CJ, Knight B, Patch AM, Ness AR, Ebrahim S, Lawlor DA, Ring SM, Ben-Shlomo Y, Jarvelin MR, Sovio U, Bennett AJ, Melzer D, Ferrucci L, Loos RJ, Barroso I, Wareham NJ, Karpe F, Owen KR, Cardon LR, Walker M, Hitman GA, Palmer CN, Doney AS, Morris AD, Smith GD, Hattersley AT, McCarthy MI: A common variant in the FTO gene is associated with body mass index and predisposes to childhood and adult obesity. Science 2007, 3 I 6(5826):889-894.

10. Groop L: From fused toes in mice to human obesity. Nat Genet 2007, 39(6):706-707.

II. Scott LJ, Mohlke KL, Bonnycastle LL, Willer CJ, Li Y, Duren WL, Erdos MR, Stringham HM, Chines PS, Jackson AU, Prokunina-Olsson L, Ding CJ, Swift AJ, Narisu N, Hu T, Pruim R, Xiao R, Li XY, Conneely KN, Riebow NL, Sprau AG, Tong M, White PP, Hetrick KN, Barnhart MW, Bark CW, Goldstein JL, Watkins L, Xiang F, Saramies J, Buchanan TA, Watanabe RM, Valle TT, Kinnunen L, Abecasis GR, Pugh EW, Doheny KF, Bergman RN, Tuomilehto J, Collins FS, Boehnke M: A genome-wide association study of type 2 diabetes in Finns detects multiple susceptibility variants. Science 2007, 3 | 6(5829): | 34|-I345.

12. Anand SS, Yusuf S, Vuksan V, Devanesen S, Montague P, Kelemen L, Bosch J, Sigouin C, Teo KK, Lonn E, Gerstein HC, Hegele RA, McQueen M: The Study of Health Assessment and Risk in Ethnic groups (SHARE): rationale and design. The SHARE Investigators. Can / Cardiol I998, I 4( I I): |349- I 357.

13. Hanley AJG, Harris SB, Barnie A, Gittelsohn J, Wolever TMS, Logan A, Zinman B: The Sandy Lake Health and Diabetes Project: design, methods and lessons learned. Chronic Dis Canada 1995 , 16:149-156.

14. Bjerregaard P, Curtis T, Borch-Johnsen K, Mulvad G, Becker U, Andersen S, Backer V: Inuit health in Greenland: a population survey of life style and disease in Greenland and among Inuit living in Denmark. Int I Circumpolar Health 2003, 62 Suppl I:3-79.

15. Alberti KG, Zimmet $P$, Shaw J: Metabolic syndrome--a new world-wide definition. A Consensus Statement from the International Diabetes Federation. Diabet Med 2006, 23(5):469-480.

16. Cardon LR, Bell Jl: Association study designs for complex diseases. Nat Rev Genet 200I, 2(2):91-99.

17. Li H, Wu Y, Loos RJ, Hu FB, Liu Y, Wang J, Yu Z, Lin X: Variants in the fat mass- and obesity-associated (FTO) gene are not associated with obesity in a Chinese Han population. Diabetes 2008, 57(I):264-268.
Publish with Bio Med Central and every scientist can read your work free of charge

"BioMed Central will be the most significant development for disseminating the results of biomedical research in our lifetime. "

Sir Paul Nurse, Cancer Research UK

Your research papers will be:

- available free of charge to the entire biomedical community

- peer reviewed and published immediately upon acceptance

- cited in PubMed and archived on PubMed Central

- yours - you keep the copyright

Submit your manuscript here:

http://www.biomedcentral.com/info/publishing_adv.asp
BioMedcentral 